\title{
Imprescriptibilidad de la acción penal en delitos sexuales contra menores
}

\author{
Carlos Cabezas Cabezas*
}

\begin{abstract}
RESUMEN
El trabajo propone discutir críticamente los fundamentos y efectos de varias propuestas legislativas actualmente en discusión en nuestro país que proponen declarar imprescriptibles los delitos de violencia sexual contra menores de edad, enfrentando dichos fundamentos con los de la prescripción penal en general y de la acción penal en particular, planteando además recomendaciones en caso de que dichas propuestas legislativas prosperen.
\end{abstract}

Delitos sexuales - menores - imprescriptibilidad

\section{Imprescriptibility of sexual crimes against children}

\begin{abstract}
The paper proposes to critically discuss the foundations and effects of several legislative proposals currently under discussion in our country to declare the offenses of sexual violence against minors not be subject to any statute of limitations, confronting those foundations with those of criminal statute of limitations in general and of criminal action in particular. And also put forward recommendations in the event that such legislative proposals are successful.
\end{abstract}

Sexual offenses - minors - statutes of limitations - imprescriptibility

* Licenciado en Ciencias Jurídicas, Universidad de Antofagasta. Magíster en Derecho y Procesos Penales, Universidad de Antofagasta. Doctor en Derecho, Universidad de Trento, Italia. Profesor de derecho penal, Universidad de Antofagasta.

Artículo recibido el 21 de agosto de 2017 y aceptado para su publicación en este número el 18 de enero de 2019. 


\section{Antecedentes}

$\mathrm{D}$ esde fines de la década de los 90 los delitos que afectan la esfera de la sexualidad humana han recibido un creciente y justificado interés ${ }^{1}$. Ya sea por su deficiente regulación previa, que los incardinaba en el confuso horizonte de los delitos contra la honestidad hasta la escasa cuantía de sus sanciones, los últimos años del siglo pasado y los primeros del presente fueron testigos de una abundante legislación que intentaba colocar a tono la legislación patria a los estándares internacionales de protección ${ }^{2}$. Este ímpetu reformador, no exento de voces críticas respecto de alguno de sus extremos ${ }^{3}$, ha disminuido en los últimos lustros pero se sigue manifestando periódicamente, en especial respecto del castigo de conductas atentatorias contra bienes jurídicos cuyos titulares son menores de edad.

Organizaciones de derechos de la infancia, colectivos y ONG de protección de minorías sexuales han reencendido el debate acerca de varios de estos delitos y últimamente respecto de la prescriptibilidad de estas infracciones. Si bien la idea de sustraer estos delitos del efecto del paso del tiempo siempre ha estado en el trasfondo de muchas de estas reformas, ha sido solo recientemente que se ha tratado de legislar directamente bajo esa premisa ${ }^{4}$. Así tenemos los proyectos de ley individualizados en los boletines refundidos $\mathrm{N}^{\mathrm{o}}$ 6956-075 , 8134-07, 10033-07, 10186-07, 10236-07, y 10784-07. Todos comparten fundamentos y parcialmente contenido. Más allá de algunas diferencias, en lo que es materia de este trabajo, todos declaran los delitos de los párrafos 5 y 6 del título VII del Código Penal (en adelante CP) imprescriptibles cuando el sujeto pasivo sea un menor de edad ${ }^{6}$. A estas mociones actualmente vigentes se han sumado iniciativas como "Abuso sexual imprescriptible"7 patrocinado por psicólogos infantojuveniles y algunos

${ }^{1}$ En este trabajo se empleará el término "violencia sexual" en lugar de "abuso sexual”, término empleado por los promotores de la reforma, por ser más ilustrativo técnicamente del fenómeno que se pretende reformar (el abuso sexual es un delito específico de la parte especial del Código).

${ }^{2}$ Las leyes 19.617 y 19.927 de 1999 y 2004, respectivamente, cambiaron el rostro del Código Penal acerca de esa familia de delitos. Para un examen de ellas, véase RodríGuez, L., Delitos sexuales, Jurídica de Chile, Santiago, 2014, pp. 95 y ss.

${ }^{3}$ Esencial, GuZmán Dalbora, J.L., “Aprobación y reprobación de la reforma de los delitos contra la honestidad en Chile”, en Anuario de Derecho Penal, N 1999-2002, pp. 201-244.

${ }^{4}$ Ímpetu que podría afectar posteriormente a otros delitos: en Perú, recientemente, el Congreso ha aprobado una reforma constitucional que modificará el art. 41 de la Carta magna de ese país para declarar los delitos de corrupción y que afecten el patrimonio del Estado como imprescriptibles.

${ }^{5}$ Este boletín ha recibido suma urgencia para su tramitación el 9 de marzo de 2018.

${ }^{6}$ Algunas diferencias importantes valen la pena ser destacadas: solo el proyecto 10784-07, patrocinado por la exdiputada Karla Rubilar declara imprescriptible también la pena, extendiéndose además a los delitos de trata de personas del párrafo V bis del Título VIII del Libro II; el proyecto 10236-07 considera imprescriptibles solo los delitos cometidos contra víctimas menores de 14 años rigiendo en cambio la actual extensión del plazo del art. 369 quater para sujetos pasivos mayores de 14 años.

${ }^{7}$ Actualmente la solicitud lleva 2.378 firmas de adhesión, las que se pueden revisar en la página http:// abusosexualimprescriptible.cl/. 
juristas que ha generado adhesión en círculos políticos y académicos, con el objetivo de apoyar las iniciativas legislativas antes individualizadas ${ }^{8}$.

La finalidad sería evitar que el no descubrimiento del delito deje a la víctima menor de edad en la total indefensión y permita la impunidad del agresor. Esta falta de descubrimiento puede originarse ya sea por el desconocimiento por parte del menor del contenido ofensivo de las acciones o por amenazas, coacciones u otro tipo de presiones bien del autor del delito, bien de la familia de la víctima o por el silencio de los propios padres y cercanos al menor como una forma de "protegerlo" o para proveer la impunidad al ofensor $^{9}$. A causa de que estos delitos pueden afectar a un sujeto a edades muy tempranas de su formación, su descubrimiento puede no producirse de inmediato o simplemente quedar en el anonimato. La solución estaría en mantener abierta indefinidamente (al menos hasta la muerte del agente) la posibilidad de investigar y juzgar a estos sujetos, lo que implica, entonces, declarar imprescriptibles estos delitos.

En 2004 estos motivos fueron los catalizadores de la reforma que incorporó el art. 369 quater al CP, el que prevé que los delitos de los párrafos 5 y 6 del Título VII del Libro II comiencen a prescribir solo desde la mayoría de edad de la víctima, lo que configura técnicamente una causal de suspensión del plazo ${ }^{10}$. El legislador presume que llegado un cierto momento, en este caso la mayoría de edad del ofendido, este posee la madurez suficiente o cuenta con los medios para desvincularse de las presiones o amenazas de las que pudo haber sido objeto y así revelar el delito, evitando de este modo la promesa de impunidad que supondría la llegada del plazo de prescripción de la acción penal ${ }^{11}$.

Actualmente se juzga dicha modificación insuficiente. Apoyándose en literatura especializada y recomendaciones de organismos internacionales como la Organización de Naciones Unidas (en adelante ONU), explican que estos plazos -en el mejor de los casos, diez años desde la mayoría de edad-serían muy exiguos, pues la evidencia apunta a que los momentos de revelación de estos actos acaecidos en la infancia se producen a edades más avanzadas y, en todo caso, luego de esos plazos máximos en los que la ley extiende la contingencia de persecución criminal que es el plazo de prescripción.

${ }^{8}$ En este trabajo se utilizará preferentemente la locución "prescripción de la acción penal”, pues es la utilizada por nuestro Código Penal, prefiriéndola a "prescripción del delito” por ser ajena a nuestra tradición.

${ }^{9}$ Cfr. moción parlamentaria que introdujo la introducción del art. 369 quater CP, boletín No 3799-07.

${ }^{10}$ En Chile no resulta tan evidente, toda vez que nuestra única causa de suspensión se produce según el art. $96 \mathrm{CP}$ al momento del que "el proceso se dirija en contra del culpable"; otras legislaciones, en cambio, identifican la postergación del dies a quo como una causa de suspensión. Véase para el Derecho italiano Fiandaca, G., y Musco, E., Diritto penale. Parte Generale, Quinta edición., Zanichelli, Bologna, 2007, p. 783; para el Derecho alemán Saliger, F., "§78 ff.”, en: KindhäUser, U., Neumann, U., y PAeffGen, H-U-. (Coords.) NomosKommentar StGB, $3^{\circ}$ edición, Nomos, Baden-Baden:, 2010, p. 2505. En Chile, en contra Peña, S., y Santibáñez, M., "La prescripción de delitos sexuales contra menores de edad. Modificaciones introducidas por la Ley $\mathrm{N}^{0} 20.207$ ”, Microjuris 2, enero 2008.

${ }^{11}$ Acerca de esta reforma y sus implicaciones jurídicas CABEzas, C., "Prescripción de los delitos contra la indemnidad y libertad sexual de los menores de edad: problemas aplicativos del artículo 369 quater del Código Penal”, en Política criminal, Vol. 8, No 16 (diciembre 2013), pp. 386-407. 


\section{LA PRESCRIPCIÓN DE LA ACCIÓN PENAL Y SU FUNDAMENTO}

\section{El fundamento de la prescripción de la acción penal}

Para juzgar estas propuestas es preciso determinar el fundamento político criminal de la prescripción de la acción penal. Los extremos de esta discusión son bien conocidos y creo que no es necesario repetirlos aquí, aunque vale la pena detenernos algunos momentos en cuáles fundamentos propuestos no son atendibles modernamente ${ }^{12}$.

A menudo se postula que el fundamento de la prescripción de la acción radica en el debilitamiento que las pruebas experimentan con el paso del tiempo, lo que redundaría en un aumento en la posibilidad de dictar sentencias erróneas ${ }^{13}$, que es el denominado, a mi juicio incorrectamente, fundamento "procesal”. Aquí ante todo, existe una confusión entre el fundamento y los efectos benéficos de una determinada institución: porque la prescripción cancela la posibilidad de juzgar hechos acaecidos a mucha distancia es que, en teoría, disminuye la posibilidad de dictar sentencias erróneas por la mejor "calidad" del material probatorio, pero no al revés. Además, es cierto que algunas pruebas se ven mucho más afectadas que otras por el transcurso del tiempo, como la prueba testimonial, pero otras no experimentan estos problemas, como las pruebas documentales ${ }^{14}$.

En segundo lugar, parece poco apropiado esgrimir la seguridad jurídica como fundamento de la prescripción. Ha sido el argumento preferido para oponerse a la imprescriptibilidad de ciertas infracciones, especialmente frente a proyectos de ley como el que analizamos aquí, por dos razones ${ }^{15}$ : la misma imprescriptibilidad atentaría contra la seguridad jurídica, y debido a la imprescriptibilidad se debilitaría la seguridad jurídica de los imputados. La diferencia estriba en que para la primera posición los delitos que no prescriben jamás serían de por sí atentados contra la seguridad jurídica, al mantener al imputado eternamente en vilo a la espera de una eventual reacción de la justicia en su contra ${ }^{16}$; la segunda, es una combinación de los argumentos procesales: la imprescriptibilidad debilita la seguridad jurídica, pues ser juzgado a tal distancia temporal aumenta las posibilidades de sentencias erróneas.

${ }^{12}$ Buenos resúmenes de los mismos se encuentran, entre otros en PEDreIdA GonzÁLEz, F., La prescripción de los delitos y de las faltas, Centro de Estudios Ramón Areces, Madrid, 2004, pp. 133 y ss.; En Chile, forzoso es recurrir al único monografista de la materia, Yuseff, G., La prescripción penal, Editorial Jurídica de Chile, Santiago, 2009, pp. 43 y ss.; BALmacedA, G., "La prescripción en el Derecho penal chileno", en Corral, H. (coord.), La prescripción extintiva, Cuadernos de extensión jurídica de la Universidad de los Andes, Santiago, 2011, pp. 175-194, pp. 176 y ss.

${ }^{13}$ Véase Binding, K, Handbuch des Strafrechts, Leipzig, 1885, p. 822 y ss.

${ }^{14}$ Cfr. Giunta, F y Micheletti, D., Tempori cedere. Prescrizione del reato e funzioni della pena nello scenario della ragionevole durata del proceso, Turín, Giappichelli, 2003, p. 41

15 Algo de ello aparece en la discusión legislativa de los proyectos antes mencionados. Véase MedinA, G., "Observaciones a proyecto de ley relativo a imprescriptibilidad de los delitos sexuales cometidos contra menores de edad”, Santiago, 16 de noviembre de 2016. También en PEDREIDA, ob. cit., p. 148 y en SÁNCHEZ Ostiz, P., Fundamentos de política criminal. Un retorno a los principios, Marcial Pons, Madrid, 2012, p. 143 y ss.

${ }^{16}$ Cfr. Silvani, S., Il giudizio del tempo. Uno studio sulla prescrizione del reato, Bolonia, Il Mulino, 2009, p. 45. 
La primera posición no es sostenible, pues que un delito sea imprescriptible no atenta contra el núcleo central del principio de seguridad y certeza jurídicas que es la previsibilidad (seguridad subjetiva ${ }^{17}$ ), de las consecuencias de una acción. Si la imprescriptibilidad está declarada en la ley -y es irretroactiva, por cierto- el individuo sabe con anticipación que la amenaza de la reacción punitiva eventual puede extenderse por toda su existencia ${ }^{18}$. Con todo, la seguridad sí juega un rol determinante en la prescripción pero a propósito de su naturaleza, como veremos más adelante.

Modernamente, la doctrina considera que existen al menos dos fundamentos. El primero es aquel que sostiene que un delito se extingue por el paso del tiempo debido a que decae la necesidad de pena ${ }^{19}$, en el sentido que una acción humana que merezca pena, con el paso del tiempo pasa a formar parte de la historia, haciendo innecesario el castigo penal $^{20}$. En este sentido también se habla de "fuerza del tiempo" en el sentido que transcurrido un cierto plazo, el olvido se cierne sobre todas las actividades humanas ${ }^{21}$.

El segundo sostiene que la prescripción de la acción penal solo se explica por razones de humanidad, en el sentido que un mínimo respeto a la dignidad del imputado y una razonable restricción del ius puniendi estatal admite que uno de los vectores de dicha restricción sea el paso del tiempo ${ }^{22}$. De este modo, el tiempo en relación no con la comunidad, sino con el sujeto, se establece como una dimensión de limitación del poder del Estado; el Estado declara, como compromiso, no mantener la contingencia de punición permanentemente abierta como forma de protección del individuo ${ }^{23}$, basado en la noción kantiana de dignidad que exige que el individuo sea el centro del mundo y de la sociedad ${ }^{24}$. así, la prescripción se justifica pues es poco factible el pleno desarrollo del individuo ahí donde pende sobre él eternamente una espada de Damocles. Como principio, la humanidad exige, entonces, que la reacción penal se justifique no solo por

${ }^{17} \mathrm{O}$ seguridad de orientación; véase Henkel, H., Introducción a la teoría del Derecho, Gimbernat, E. (trad.), Taurus, Madrid, 1968, p. 547; López de OÑATe, F., La certezza del diritto, Giuffrè, Milán, 1968, p. 48.

${ }^{18}$ Cfr. Ragués, R., La prescripción penal: fundamento y aplicación, Atelier, Barcelona, 2004, p. 28.

${ }^{19}$ En Italia, la gran mayoría de los autores juzga esta posición como correcta. STORTONI, L., "Estinzione del reato e della pena", en Dig. discp. pen., pp. 342.359, p. 346; SANToro, A., "Estinzione del reato e della pena”, en Nov. dig. it., vol. VI, Turín, 1960, pp. 991-996, p. 992; Marinucci, G., y Dolcini, E., Manuale di Diritto penale. Parte generale. $4^{a}$ edición, Giuffrè, Milán, 2012, p. 378; Panagia, S., "Voz Prescrizione del reato e della pena”, en Dig. disc. pen., 1995, pp. 659-670, p. 661; Donini, M., Teoria del reato. Una introduzione, Cedam, Padua, 1996, p. 409.

${ }^{20}$ Habría que reconocer en estas vertientes a Balmaceda, ob. cit., p. 178 y Raguès, ob. cit., p. 45. Dichos autores se refieren a este fundamento como aquel orientado a los fines del Derecho penal.

21 Así Viganó, F., "Nuove prospettive per il controllo di costituzionalità in materia penale?" Giur. cost. 2010 p. 3017-3030 p. 3021 quien lo vincula a la prevención general de la pena.

22 Así en la doctrina nacional GuZmán Dalbora, J.L., "Crímenes internacionales y prescripción" en Temas actuales del Derecho penal internacional, Konrad Adenauer Stiftung, Montevideo, 2005, pp. 103-115, p. 108; también Cabezas, ob. cit., p. 394.

${ }^{23}$ Mañalich, J.P., Terror, pena y amnistía, Flandes Indiano, Santiago, 2010, p. 212.

${ }^{24}$ Esta noción de humanidad encuentra su origen en la filosofía de Miguel de Unamuno y en las obras de Rudolph Stammler, consideradas por Recasens Siches. Cfr. Recasens Siches, L., Filosofía del Derecho, Porrúa, México, 1961, pp. 531 y ss. 
la conducta del sujeto (típica, antijurídica y culpable) sino también por los restantes presupuestos de la punibilidad, entre ellos, el factor temporal, irrogándose solo dentro de un espacio temporal delimitado por la ley. Esto se explica porque solo de este modo pueden asegurarse niveles de autorrealización aceptables, autorrealización que se vería amenazada por un estado de permanente "disponibilidad" del individuo para el poder punitivo del Estado, lo que a menudo podemos relacionar con la noción de pertinencia de la sanción penal ${ }^{25}$. A la vez, desde esta perspectiva la seguridad jurídica se transforma no en fundamento de la prescripción del delito, sino en el fundamento de su naturaleza sustantiva en su concepción objetiva, es decir, como protección de la confianza o protección de la objetividad o no modificación de las reglas del juego ${ }^{26}$.

La noción de necesidad de pena es criticable pues si el fundamento de la prescripción es la no necesidad de pena por el mero transcurso del tiempo, ello convierte al legislador en una suerte de clarividente que puede determinar cuándo, en el futuro, una comunidad considerará que un delito que merecía una sanción penal ya no la requiere. Por ello, en este trabajo, se sostiene como fundamento de la prescripción de la acción penal el respeto al principio de humanidad. Con todo, no está claro si el respeto a dicha humanidad sea exigible, en lo que a prescripción se refiere, para todo delito, especialmente con aquellos de gravedad superlativa, como veremos en el siguiente acápite.

\section{El fundamento de la imprescriptibilidad}

Lo anterior haría concluir, entonces, que los delitos, todos, deberían prescribir. Las legislaciones del derecho continental siguen mayoritariamente esta premisa, pero muchas consideran desde antiguo, delitos imprescriptibles y hoy el Derecho internacional y buena parte de las legislaciones del mundo cancelan la extinción de la responsabilidad penal por el paso del tiempo en los crímenes de genocidio, lesa humanidad y de guerra.

Sin embargo, hay que reconocer que el legislador no parece estar limitado constitucionalmente a la hora de declarar una infracción penal como imprescriptible. No se trata de una garantía expresa en el ordenamiento. Se trata de una decisión de política criminal respecto de las cuales el legislador es libre para decidir, aunque, por cierto, esa libertad se encuentra determinada y limitada por algunos fines.

Así, podemos observar que, desde antiguo, la prescripción penal existe como regla general en la mayoría de los ordenamientos jurídicos occidentales, mientras la imprescriptibilidad aparece como una excepción. Según lo razonado en el acápite anterior, si la prescripción se fundamenta en principios, ahora entonces podría decirse que la mayoría de las infracciones penales deberían prescribir, mientras que, excepcionalmente, algunas

${ }^{25}$ LÓpeZ de OÑATE, op. cit., p. 72.

${ }^{26}$ En este sentido me parece que se orienta la noción de seguridad jurídica construida por Pérez Luño A. "La Seguridad jurídica: una garantía del derecho y la justicia”, en Boletín de la Facultad de Derecho, No 15 , 2000 , pp. 25-38, en el sentido que, luego de pasar revista a las situaciones en las que la seguridad jurídica es manipulada por regímenes de facto o totalitarios, concluye que esa noción de seguridad en la inseguridad "sin incompatibles con la razón de ser del Estado de Derecho. 
infracciones podrían mantenerse indiferentes al paso del tiempo. Entre medio, existen muchas alternativas para alargar los plazos de prescripción, modulando los fundamentos de la institución a partir de otros fines contrapuestos.

Tradicionalmente, el criterio para considerar una infracción imprescriptible es la gravedad asociada al delito. Así lo demuestran las legislaciones que mantienen la prescriptibilidad como regla general pero reservan a algunos delitos esta característica, como el homicidio agravado. Es también el fundamento utilizado a menudo para justificar la imprescriptibilidad de los crímenes de lesa humanidad. El fundamento es fácil de rastrear: a mayor gravedad material del ilícito, decaen los motivos que la fundamentan; así, de un delito muy grave por atentar contra bienes jurídicos de superlativa importancia ( $v . g$. , la vida) no puede predicarse que deja de ser necesaria la pena solo por el largo transcurso del tiempo; o que el respeto a la humanidad del reo cede aquí por las también excepcionales consecuencias de su obrar. En cierto sentido, la prescriptibilidad de una acción medida de acuerdo con su ofensividad es un argumento para defender la naturaleza sustantiva de este instituto ${ }^{27}$.

Sin embargo, si nos remontamos brevemente en la historia de la prescripción, podremos comprobar que este argumento no es del todo efectivo o al menos no explica del todo la institución ${ }^{28}$. Vale la pena recordar el caso de Alemania, país que en dos oportunidades durante el siglo XX ha debido enfrentarse a esta delicada cuestión. La solución de la imprescriptibilidad fue la primera opción: con la ley de cálculo impulsada por las potencias vencedoras luego de la Segunda Guerra Mundial, se trabajó aun dentro de los márgenes de la prescripción penal, aplicando un típico instituto de esta: la suspensión. Se alegó que no era posible considerar el tiempo en que el horror nazi era una práctica del propio Estado alemán, pues ¿qué voluntad existiría de perseguir los delitos cometidos por propia iniciativa? En este caso ninguna contingencia de punición se habría activado: esta era del todo imposible. Solo después de comprender que la magnitud de esos crímenes superaba con creces las posibilidades y recursos de un Estado, se fue pasando sucesivamente hacia la solución de la imprescriptibilidad ${ }^{29}$. Es, en el fondo, el reconocimiento que la monstruosa criminalidad del nacionalsocialismo fue un fracaso del ${ }^{30}$ Estado de Derecho por lo que, malamente, pueden oponerse mecanismos como la prescripción que funcionan en situaciones de normalidad.

${ }^{27}$ Cfr. Jescheck, H-H., Tratado de Derecho penal. Parte general, Mir Puig, S., y Muñoz Conde, F. (trad.), tomo II, Barcelona, Bosch, 1978, p. 1239.

${ }^{28}$ Mientras que en la Antigüedad la regla era la imprescriptibilidad, después de la Revolución Francesa el criterio cambia radicalmente, pasando a ser la regla general la prescriptibilidad de todo delito. Ese período histórico se mantiene, con algunas excepciones, hasta la segunda mitad del siglo XX. Véase SiLVANI, S., Il giudizio del tempo. Uno studio sulla prescrizione del reato, Bolonia, Il Mulino, 2009, p. 17 y ss.

${ }^{29}$ Sobre este proceso Dannecker G., Das intertemporale Strafrecht, Mohr, Tubingen, 1993, p. 325 y ss y y Sambale A., Die Verjährungsdiskussion im Deutschen Bundestag, Kovac, Hamburgo:, 2002, pp. 64 y ss; Vassalli, G., Formula di Radbruch e diritto penale, Giuffrè, Milán, 2001, passim. Incluso se ha planteado derechamente y sin ambages que la solución tiene un fundamento meramente político: véase HoNG, Y., Zeitablauf als Grenze des staatlichen Strafanspruchs, Peter Lang, Frankfurt, 2005, p. 35.

${ }^{30}$ Mañalich, JP., Terror, pena y amnistía, Flandes Indiano, Santiago, 2010, p. 30. 
En este orden de ideas, me parece que lo que justificaría la imprescriptibilidad de los delitos contra la humanidad no es (solo) la gravedad material de estos delitos (la que no se desconoce ${ }^{31}$ ), sino su contexto: si la voluntad de perseguir dichos ilícitos no existe, entonces mantener los plazos de prescripción del derecho interno resulta absurdo, cuando no un auténtico fraude a las legítimas aspiraciones de castigo y reparación. Si la perpetración de un delito contra la humanidad importa un fracaso del Estado de Derecho -porque el mismo Estado es su perpetrador o lo ha permitido sin serlo- resulta entonces poco recomendable considerar que al tiempo de su comisión alguna posibilidad de persecución y castigo pudiese darse. Además, otra característica predicada de estos delitos, es decir, su escala más o menos industrial -de la que Auschwitz es su triste epígono-, implica que estos atroces hechos difícilmente pueden ser realizados por una o algunas pocas personas, requiriéndose en la mayoría de los casos el concurso de aparatos estatales o de similares características. Esta escala (que abarque muchos ejecutores o que estos se hayan visto beneficiados por la cobertura del Estado para cometerlos y permanecer en la impunidad, o ambos) justifica el recurso al instrumento de la imprescriptibilidad.

En otras palabras, lo que justificaría la imprescriptibilidad en el caso de los crímenes de lesa humanidad y genocidio es la gravedad material de estos delitos, acompañada de su ejecución a gran escala, lo que condiciona negativamente la posibilidad de su persecución y juzgamiento (imposibilidad fáctica).

Entiendo aquí por "gravedad material" aquella que se desprende del concepto de antijuridicidad material o lesividad del delito, es decir, grave tanto por la calidad y jerarquía del bien jurídico tutelado como por la forma del ataque que sufre ${ }^{32}$.

Ahora, cuando estamos en presencia solo de gravedad material, las legislaciones suelen reservar la imprescriptibilidad para delitos que atentan contra bienes jurídicos de superlativa relevancia, como la vida; es el caso del asesinato, imprescriptible en varias legislaciones ${ }^{33}$. En cambio, cuando solo la posibilidad de juzgamiento (imposibilidad fáctica) se ve comprometida, las legislaciones reservan otro tipo de mecanismos para superar dichas imposibilidades, recurriéndose entonces a la suspensión o interrupción del plazo, de modo tal que el tiempo transcurrido entre el momento de la perpetración del delito y su descubrimiento sea inútil para cualquier cómputo. Este es el fundamento de normas existentes en nuestro ordenamiento, como el art. $101 \mathrm{CP}$ y del 369 quater $\mathrm{CP}^{34}$.

${ }^{31}$ Con todo, es preciso notar que la gravedad de muchas infracciones del Derecho penal internacional no es equivalente a los más graves atentados contra la humanidad que allí se contemplan.

32 Sánchez Ostiz, Fundamentos de política criminal, Madrid, Marcial Pons, 2012, p. 152; Ossandón, María Magdalena, La Formulación de tipos penales, Santiago, Editorial Jurídica de Chile, 2009, p. 469.

33 En estos casos habría que reconocer que solo la antijuridicidad material justificaría la extensión de los plazos.

${ }^{34}$ Con todo, este segundo mecanismo ha sido utilizado también para el juzgamiento de crímenes de lesa humanidad cometidos por Estados no democráticos, como sucedió en el caso uruguayo al momento de juzgar a uno de sus dictadores, José María Bordaberry. Véase al efecto ForNASARI, G., "Dittatori alla sbarra: il caso Bordaberry come pietra miliare della giustizia di transizione in Uruguay" en Studi in onore di Mario Romano, vol. IV, Jovene, Nápoles, 2011, p. 2295 y ss. 


\section{La imprescriptibilidad y su fundamento en los proyectos de ley}

Establecidas las bases tanto del fundamento de la prescripción como de la imprescriptibilidad, es el momento de hacerse cargo de los fundamentos presentados en los proyectos de ley antes reseñados.

Los diversos proyectos mencionados previamente se centran en la siguiente batería argumental: 1) los menores que sufren de este tipo de abusos no están en condiciones de revelar su acaecimiento dentro de los tiempos de prescripción ya modificados por la norma del art. 369 quater, pues la reconstrucción del relato se produce solo a edades más avanzadas difíciles de determinar con precisión; 2) documentos internacionales declaran que el abuso sexual infantil es asimilable a delitos como la tortura, lo que justifica un régimen similar; 3) aun levantando estas barreras, los denunciantes se enfrentan con un sistema no diseñado para ocuparse eficazmente de ellos, lo que nuevamente justificaría no contemplar plazo alguno.

3.1. La imprescriptibilidad sería la única forma de asegurar el acceso a la justicia de parte de las víctimas

Respecto del primer argumento se trata del principal para ampliar los plazos de prescripción o eliminarlos absolutamente: las víctimas no han tenido la oportunidad real de acceder a la justicia. Como hemos visto, las razones para declarar un delito imprescriptible (es decir, que la contingencia de la punición no esté limitada o condicionada por el tiempo) puede radicar en la gravedad material del delito y en la ejecución a gran escala de los mismos. Como reconocen los autores de la propuesta no sería este el motivo (a pesar de que se trata de delitos graves), sino la imposibilidad de ejercer la acción penal en forma tempestiva (es decir, la imposibilidad fáctica).

Como revisamos en el apartado anterior, la mera imposibilidad fáctica de perseguir un delito no transforma ese ilícito en nuestro ordenamiento per se en uno que merezca un régimen de imprescriptibilidad, sino uno de suspensión o interrupción de los plazos; a causa de que los menores víctimas de dichos ilícitos se encuentran encerrados en un círculo de abuso del que no pueden salir por sí mismos, una tutela adecuada de sus bienes jurídicos puestos en riesgo o lesionados exigiría no considerar el tiempo que media entre la comisión del ilícito y su descubrimiento. Pero, y ya que la imposibilidad no es absoluta, pues los autores de dichos delitos no pertenecen al aparato estatal o similares (es decir, no es criminalidad del Estado), el mantenimiento de la apertura de la contingencia punitiva no debería extenderse en forma indefinida, sino modularse estableciendo hitos en los que pueda, abstractamente, determinarse en qué momento esa imposibilidad relativa decae y las víctimas de los delitos están en condiciones de revelar lo sucedido. Es decir, los fundamentos del art. 369 quater del CP.

Quienes sostienen los proyectos de ley presentados no están de acuerdo. Para ello se apoyan en estudios criminológicos en que se ha determinado que la edad de revelación de los mismos es fluctuante, pero que superaría con creces incluso el plazo dispuesto ya 
en el art. 369 quater $^{35}$. A ello se suma otro argumento: el derecho "al tiempo" 36 como patrimonio de las víctimas y que debiese ser respetado por el legislador, cancelando los plazos prescriptivos de estos delitos.

El derecho al tiempo consistiría en el derecho a perseguir delitos en el momento en que las víctimas estén en condiciones de hacerlo, sin estar sujetos a plazos u otras condiciones. El concepto de derecho al tiempo se basa en la noción de empatía, es decir, en un sentimiento de identificación de un sujeto con los demás, para "vivenciar de manera intersubjetiva las afecciones a las que puede llegar a abrigar, siempre tomando como referencia una situación límite o autoevidente, es decir, la facultad de reproducir lo que el otro siente, piensa o experimenta" ${ }^{37}$. En este contexto, las exigencias derivadas del concepto de empatía en el Derecho obligarían a legisladores y jueces a colocarse en el lugar, en este caso de la víctima y respetar el proceso interno de elaboración de la propia memoria y reconstrucción de los hechos, habida cuenta de los severos daños neurocognitivos que producen los delitos de violencia sexual en los menores. En conclusión, impedimentos temporales de carácter legal deben ser removidos para permitir a las víctimas acceder a la justicia.

Ahora bien, más allá de considerar a la empatía como un concepto o principio vigente de nuestro ordenamiento, la pregunta es si su inclusión obliga o no a la reparación

${ }^{35}$ Entre los informes presentados a la comisión de legislación de la Cámara de diputados se encuentra la presentación de JACKson, V., y HAMilton, J., "Imprescriptibilidad del abuso sexual y derecho al tiempo", presentación de 7 de septiembre de 2016. En él se indica que "la vulnerabilidad mayor en los seres humanos es durante la niñez, y los crímenes en esta etapa tienen un carácter único: por su edad, las víctimas no tienen cómo entender, resistir, escapar, protegerse o responder ante eventos que superan sus umbrales de defensa psíquica y física" (p. 3). Luego, se remiten a un estudio (Arredondo, V., Saavedra, C., Troncoso, C. \& Guerra, C., "Develación del abuso sexual en niños y niñas atendidos en la Corporación Paicabi", Revista Latinoamericana de Ciencias Sociales, Niñez y Juventud, 14 (1), 2016, pp. 385-399) para indicar que solo un tercio de los menores revelan tempranamente el haber sido víctima de un abuso (p. 8). Lo que la presentación olvida, es que para el estudio citado, revelación temprana es aquella que se produce en un plazo de 1 mes luego del abuso, intermedio aquel que se produce entre uno a seis meses y tardío cuando la revelación supera los 6 meses (Arredondo et al., op. cit., p. 389). La omisión es relevante, pues luego el informe de Jackson y Hamilton asegura que literatura internacional -que no es citada- el tiempo de revelación fluctúa entre 10 y 20 años.

36 Jackson y Hamilton, ob. cit., p. 12

${ }^{37}$ Carreón Perea, M., "Apuntes sobre la empatía y los derechos humanos”, en Iter criminis, $\mathrm{N}^{\circ} 10$, VI época, julio-septiembre 2015, pp. 79-90, p. 83. El origen del concepto de empatía puede rastrearse, a mi juicio, hasta los trabajos de Karen Gilligan acerca de la noción de cuidado (care). Acerca de algunos aspectos de estas teorías en sentido expositivo, me remito al trabajo de García Amado, J.A., “'Tienen sexo las normas? Temas y problemas de la teoría feminista del derecho", en Anuario de Filosofía del Derecho, IX, 1992 , p. 13-42, quien resume así la contraposición entre un derecho masculino y uno femenino: "Para la ética de justicia o de derechos la reflexión moral consiste en la elección imparcial y racional de principios y en la aplicación de estos. Estos principios u reglas tendrían carácter y alcance general y sirven para otorgar derechos u obligaciones con ese mismo alcance, debiendo estar también jerarquizados esos derechos con el fin de poder ponderar, de modo objetivo y neutral, su respectivo peso en caso de conflicto. Por contra, para la ética del cuidado lo que cuenta por encima de la aplicación de cualquier principio o norma abstracta es la apreciación del contexto de cada conflicto y la consideración de las personas implicadas, haciendo prevalecer el elemento afectivo y emocional y la voluntad de ayuda sobre la frialdad y el distanciamiento de cualquier regla”, p. 16. 
por vía penal. Es decir, si del respeto al tiempo de las víctimas se colige directamente la obligación de perseguir y condenar penalmente a un sujeto.

A mi juicio esta conexión no es del todo clara, porque de ella se seguiría, entonces, que la víctima tendría un derecho a la pena del autor. Es decir, que ese proceso de reconstrucción del severo trauma vivido en la niñez o adolescencia se repararía por medio de una sanción punitiva ${ }^{38}$. Esta afirmación nos obliga a revisar, brevemente, el papel de la víctima en el Derecho penal.

Como sabemos, el proceso de "confiscación” (o neutralización) de la víctima tiene antecedentes en la historia ${ }^{39}$ siendo precedido por un período de protagonismo y luego de redescubrimiento ${ }^{40}$. En términos simples, la víctima quedó relegada a mero objeto dentro del proceso penal en pos de una progresiva racionalización del poder punitivo por varias razones: el conflicto penal dejó de ser un conflicto entre privados, al asignarse un interés prevalentemente público en su resolución (conflicto autor-autoridad) ${ }^{41}$ a ello se agrega el temor que la víctima, en ejercicio de atribuciones privadas, pueda desencadenar una venganza incontrolable contra el autor. Así, los conflictos penales fueron monopolizados por el Estado, relegando a la víctima a un rol menor y casi inexistente. También la diferencia de bindinguiana memoria entre pena y resarcimiento, en el sentido que la segunda, que beneficia al ofendido por el delito no puede considerarse sanción, sino anulación de una situación reparable contraria al derecho jugó un rol preponderante en esta relegación ${ }^{42}$.

Solo posteriormente a la Segunda Guerra Mundial la víctima, especialmente en el Derecho penal internacional, comenzó a ser revalorada como sujeto de derechos e individuo de importante significación en el tejido social ${ }^{43}$. Luego, este progresivo redescubrimiento de la víctima fue traspasado al Derecho y proceso penal de cada Estado de la mano de movimientos como el abolicionismo que buscaban, en su empeño por humanizar el derecho penal, encontrar formas de solución de conflictos penales que

${ }^{38} \mathrm{Si}$ bien es cierto las propuestas legislativas objeto de este trabajo no declaran en ningún momento inscribirse o desear inscribirse en el marco de las teorías de la justicia restaurativa, la utilización del término "reparación" invita al menos a observar, de pasada, si el derecho a la pena como forma de reparación puede contemplarse. La respuesta, por lo pronto, parece negativa. De hecho, las teorías acerca de la justicia restaurativa contienen en sí la noción de reparación, en la que no está pensada necesariamente -y diríase mejor, en forma precisamente excluyente de- la imposición de penas tradicionales. Véase por todos Roxin, C., "La reparación en el sistema de los fines de la pena", en De los delitos y las víctimas, Ad-Hoc. Buenos Aires, 1992, pp. 129-156. Acerca de las dificultades que presenta el problema de las alternativas a la pena, véase Galain, P., "Reflexiones sobre alternativas a la pena y una aproximación a la alternatividad penal", en Doctrina y jurisprudencia penal. Términos anticipados, $\mathrm{N}^{\circ} 24$, Thompson Reuters, Santiago, 2015, pp. 3-36, p. 6.

39 Zaffaroni, E., En torno a la cuestión penal, BdF, Montevideo, 2005, p. 11.

40 García Pablos, A., Criminología, LexisNexis, Santiago, 2008, p. 62.

${ }^{41}$ Duce, M., "Algunas Reflexiones sobre los Derechos de las Víctimas en el Proceso Penal Chileno", en VV.AA., "La víctima en el sistema de justicia penal. Una perspectiva Jurídica y criminológica" Polít. crim. Vol. 9, $\mathrm{N}^{\mathrm{o}} 18$ (Diciembre 2014), Doc. 1, pp. 739-815, p. 741.

42 Eser, A., Acerca del renacimiento de la víctima en el procedimiento penal, Ad-Hoc, Buenos Aires, 1992, p. 61.

43 Bonet, M., La víctima del delito, McGraw-Hill, Madrid, 1999, p. 2. 
tuviesen a la pena como una posibilidad remota o inexistente ${ }^{44}$. El éxito más importante de estos movimientos fue la noción de "mediación penal" englobada dentro del concepto de "justicia restaurativa" 45 , la que presenta avances de importancia en la justicia punitiva anglosajona y, con menor extensión, en la alemana, justicia que busca que la reparación del daño causado por el delito se convierta en un insumo importante para acceder a mecanismos de reacción penal que otorguen mayor relevancia al ofendido por el delito, contribuyendo así a la humanización de las penas en general.

Este redescubrimiento de la víctima tiene muchos adeptos en el mundo político y en la comunidad en general, pero desde una perspectiva diversa: a causa de que se tiende a considerar al proceso penal como uno que se concentra casi exclusivamente en la protección de los imputados y poco en el perjudicado por el delito (situación injusta, según estos sectores), el redescubrimiento de la víctima presenta una faceta menos "saludable" de la mano de movimientos que buscan no dejar espacio a la impunidad y que ven el castigo (sin reparación) del imputado como un derecho de la víctima ${ }^{46}$.

Con todo, existen a juicio de buena parte de la doctrina motivos para considerar con cautela este nuevo posicionamiento de la víctima, toda vez que se reconoce que el proceso de confiscación del derecho a castigar del Estado fue un triunfo de la racionalidad moderna. Se alega que difícilmente logra conciliarse con las finalidades de la pena ${ }^{47}$ o que la presencia de la víctima como interviniente no solo en materia adjetiva sino sustantiva distorsiona el carácter eminentemente público del derecho penal; o que estas reformas en lugar de favorecer a la víctima han terminado por invisibilizarla más ${ }^{48}$.

El otro peligro asociado a conceder más intervención a la víctima está determinado por el fenómeno del neopunitivismo o el derecho de la víctima a la justicia y el castigo, rasgos que se han desarrollado sobre todo gracias a la labor de la Corte Interamericana que estaría creando un verdadero catálogo de derechos de la víctima de espaldas a la legislación y a costa de una reducción de las garantías de los imputados ${ }^{49}$. Es decir, el nuevo protagonismo asociado a la víctima aquí aparece como una decidida forma de

${ }^{44}$ Carnevali, R., "Las políticas de orientación a la víctima examinadas a la luz del derecho penal", en Revista de Derecho de la Pontificia Universidad Católica de Valparaíso, XXVI, 2005, Semestre I), pp. 27-39, p. 30.

45 Díaz, A., "La experiencia de la mediación en Chile", en Polít. crim. Vol. 5, No 9 (Julio 2010), Art. 1, pp. 1-67, p. 2.

${ }^{46}$ Silva SÁnChez, J.M., “¿Nullum Crimen sine Poena? Sobre las doctrinas penales de la "lucha contra la impunidad" y del "derecho a la víctima al castigo del autor", en Derecho Penal y Criminología, vol. 29, número 86-87, 2008, pp. 149-171, p. 160.

47 Carnevali, ob. cit., p. 34.

48 Ortiz de Urbina, I., "El renacimiento político-criminal de la víctima: una buena idea con desarrollos problemáticos", en VV.AA., "La víctima en el sistema de justicia penal. Una perspectiva jurídica y criminológica”, Polít. crim. Vol. 9, N 18 (Diciembre 2014), Doc. 1, pp. 739-815, p. 766.

${ }^{49}$ Malarino, E., "Activismo judicial, punitivización y nacionalización. Tendencias antidemocráticas y antiliberales de la Corte Interamericana de Derechos Humanos", en Sistema interamericano de protección de los derechos humanos y Derecho penal internacional, Montevideo, Konrad Adenauer Stiftung, 2010, pp. 25-64, p. 46; Silva SÁnchez, op. cit., p. 164. Muy crítico Matus, J.P., "Víctima, idealismo y neopunitivismo en el Derecho penal internacional”, en Revista Nuevo Foro Penal, Vol. 9, No 81, julio-diciembre 2013, pp. 139-145. 
limitar derechos del imputado, el centro de atención de la justicia punitiva desde la Revolución Francesa al menos.

¿Son los proyectos presentados manifiestaciones de neopunitivismo asociados a la introducción de los derechos de las víctimas? Ello depende de las finalidades que persiguen estas medidas. Si la finalidad es siempre la punición del autor, la medida podría encausarse dentro del paradigma del "derecho al castigo" y, por tanto, ser objeto del blanco de las críticas reseñadas precedentemente.

Parece difícil desde este punto de vista desconocer el giro neopunitivista de las medidas presentadas a discusión legislativa. Algo de esos rasgos están en algunos documentos y presentaciones entregadas a la comisión de legislación y justicia de la Cámara de diputados ${ }^{50}$, pues sostienen con vehemencia que la única forma de reparación a las víctimas está en la imposición de una pena, previa reconstrucción de la verdad de los hechos.

Aquí existen tres puntos que parece preciso tratar por separado: en primer lugar, no se encuentra consagrado ni a nivel internacional ni interno un derecho de las víctimas al castigo del autor ${ }^{51}$ que haga que cualquier medida que conduzca a la impunidad sea considerada ilegítima ${ }^{52}$. Segundo, que el derecho a la verdad exista como tal -esto es, a establecer la verdad de la ocurrencia de un hecho- y que, consecuentemente, ese derecho penal pueda ser realizado efectivamente en sede procesal es altamente discutible, cuando no una mera ilusión, debido a las características del proceso penal rodeado de garantías que se opone ontológicamente a la determinación de la "verdad" material ${ }^{53}$ y, tercero, que de la averiguación de la verdad se siga deontológicamente una sanción penal, ni siquiera en materia de delitos contra la humanidad, es una afirmación con características de absoluta. En este último punto, no parece desdeñable la alternativa enmarcada en

${ }^{50}$ Por ejemplo el informe ya citado de Jackson y Hamilton: "no sé cómo, en nuestro sano juicio, podemos atrevernos a establecer límites mandatarios o siquiera 'deseables' para el dolor humano y su necesidad de contención, de testimonio, de trato justo. No se puede extinguir la posibilidad de justicia para víctimas que nunca renunciaron a derechos de denuncia y/o prosecución de acciones en la justicia. Simplemente no sabían, no podían; nunca estuvieron en condiciones de comprender el crimen, ni de elegir o renunciar a nada" (p. 9). O "muchos hemos querido pensar que la ética del cuidado humano no es separable de la justicia; que las leyes son herramientas al servicio de la sociedad, de la protección de la niñez, como una prioridad irrecusable. Pero aquí nos enfrentamos al argumento de tiempos transcurridos y prescripciones que, como certeza, solo sirven a abusadores sexuales" (p. 10, las cursivas son mías).

${ }^{51}$ Cfr. Silva SÁNCHEZ, ob. cit., p. 166 para el caso español, cuyas conclusiones pueden extenderse al caso chileno.

52 En cuanto a nuestro sistema regional, el art. 63.1 de la CADH se refiere solo al derecho a la reparación, aunque es cierto que la Corte Interamericana de Derechos Humanos ha venido interpretando dicha norma en términos, por decir lo menos, amplios. Cfr. Galain, P., "Relaciones entre el derecho a la verdad y el proceso penal. Análisis de la Jurisprudencia de la Corte Interamericana de Derechos Humanos", en Sistema interamericano de protección de los derechos bumanos y derecho penal internacional, vol. II, Montevideo, Konrad Adenauer Stiftung, 2011, pp. 249-282.

53 Que el proceso penal es un mal "lugar” para la afirmación de la verdad. Así, según Galain, ob. cit., p. 265, "El proceso penal de nuestros días no tiene como objetivo la búsqueda de la verdad material, porque la lógica económica o de negociación se ha instaurado en el proceso penal, cambiando algunos paradigmas en el procedimiento de verificación de la responsabilidad penal". 
modelos de justicia restaurativa que impliquen la averiguación de la verdad (mediante investigaciones oficiales o con la propia confesión y admisión de responsabilidad del autor del delito), pero que no finalicen en una condena. Si el hecho de denunciar y dar a conocer el delito del que se fue víctima ayuda a repararla, entonces esa verdad oficial bastaría a efectos de la superación del trauma sin necesidad de recurrir a la pena ${ }^{54}$.

A lo anterior se suman otras consideraciones. Nuestro régimen de determinación de los plazos de prescripción se encuentra notablemente constreñido por la normativa del Código que distingue fases o tramos de plazo dependiendo de la cuantía de la pena. Ello implica que si las sanciones son bajas, traerán como consecuencia un plazo de prescripción breve o exiguo. Si a ello se suma un régimen de suspensión e interrupción del plazo particularmente escueto, a diferencia de otros ordenamientos, entonces puede comprenderse que los autores de estas propuestas prefieran la imprescriptibilidad antes que perfeccionar un régimen de suspensión que, a juicio de parte de nuestra doctrina, aceptaría situaciones de paralización del plazo basados en la imposibilidad del ejercicio de la acción. Sin embargo, no me parece imposible e incluso necesario para otras categorías de delitos y víctimas que comparten algunas de las características enunciadas previamente.

Finalmente, este fundamento para la ampliación de los plazos no se justifica frente a la prescripción de la pena, pues en este caso el delito ha sido descubierto, juzgado y el autor condenado, por lo que malamente podría decirse que la víctima se ha visto privada del acceso a la justicia en este caso.

3.2. La imprescriptiblidad de los delitos de violencia sexual contra menores es exigible pues se asimila a la tortura

Un segundo argumento empleado por los promotores de la imprescriptibilidad de estos delitos proviene de la exigencia emanada de organizaciones internacionales en el sentido de asimilar la violencia sexual contra menores a la tortura. Esto aparece de manifiesto en las Observaciones finales del Comité de los Derechos del Niño de la ONU respecto de los informes periódicos cuarto y quinto combinados de Chile, en el que se recomienda al Estado chileno que "tenga en cuenta la recomendación formulada por el Comité contra la Tortura en 2009 (véase CAT/C/CHL/CO/5, párr. 10) e introduzca en el Código Penal una disposición en que se establezca que el delito de tortura de niños no prescribe". Luego, combinando estas Observaciones con el Informe del Relator Especial sobre la tortura y otros tratos o penas crueles, inhumanos o degradantes de la Asamblea General de la ONU que indica que "está demostrado que la violación y otras formas de violencia sexual pueden constituir tortura y malos tratos”; así entonces se construye el argumento: porque la tortura contra niños debe ser imprescriptibile y que la violencia

54 Así lo atestiguan los procesos de justicia restaurativa en general, que precisamente por medio de alternativas penales evitan la punición con una batería de mecanismos que van desde amnistías (no autoamnistías) hasta juicios de paz y comisiones por la verdad. Cfr. Fornasari, G., Giustizia di transizione e diritto penale, Giappichelli, Turín, 2013, especialmente para la experiencia sudamericana pp. 61 y ss. 
sexual contra menores es asimilable a la tortura, la violencia sexual contra menores debe ser imprescriptible.

Más allá de considerar más o menos correctas las recomendaciones de estos organismos internacionales, vale la pena detenerse en el procedimiento hermenéutico utilizado: el Informe del relator especial no asegura que la violencia sexual contra menores sea tortura, sino que pueden constituir torturas, es decir, allí donde participen de las características de la tortura como ilícito -que, de paso, justifican que sea un delito imprescriptible-, es decir: que estos tratos inhumanos y crueles de gravedad superlativas sean realizados al amparo de un aparato estatal (o similar) que elimine en forma absoluta la posibilidad de recurrir a su auxilio para detenerlas o sancionarlas ${ }^{556}$. Asimilar-como parecen hacer los partidarios de la imprescriptibilidad-que la violencia sexual contra menores a la situación de absoluto desamparo de la víctima es un exceso interpretativo que más bien parece un forzado acomodo. Ciertamente los menores pueden verse privados en mayor o menor medida del acceso a la justicia estatal por las razones previamente dichas, pero ello no puede predicarse en términos absolutos o cuasi absolutos como cuando se trata de tortura cometida por aparatos estatales o por quienes desarrollen funciones públicas. El hecho que anualmente se denuncien, persigan y sancionen delitos de esta índole en forma más o menos constante permite discutir dicha afirmación.

${ }^{55}$ Recordemos las palabras de MAinOfER, W., Estado de Derecho y dignidad humana, trad. Guzmán Dalbora, J.L., BdF, Montevideo, 2008, p. 19: "De suerte que el funcionario público que me golpea y atormenta a su antojo, no solo lesiona únicamente mi cuerpo: destroza entre nosotros, con efectos tanto para sí mismo como para los demás, el contrato social dentro de cuyos límites ha de moverse, en la humana situación cultural, toda conducta hombre a hombre, sean cuales fueren su papel social o su condición".

${ }^{56}$ Después de la introducción de la Ley N² 20.298 de 22 de noviembre de 2016, nuestro ordenamiento finalmente adoptó la terminología "tortura", reemplazando los vocablos "tormentos y apremios ilegítimos" colocándose así a tono con la legislación internacional, especialmente con la Convención contra la tortura y otros tratos o penas crueles, inhumanas o degradantes de 1984, cambiando así también el bien jurídico tutelado de la libertad y seguridad por la protección de la vida e integridad física o psíquica de la persona; pero se mantiene en la tipicidad la exigencia que se trate de un empleado público el sujeto activo o un particular que los ejecuta en ejercicio de funciones públicas (Cfr. Matus, J.P., y Ramírez, M., Manual de Derecho penal chileno. Parte especial, Tirant lo Blanch, Valencia, 2017, p. 192 y ss.). Los tratados internacionales, en todo caso, son oscilantes en la materia. En ocasiones exigen que se trate de agentes estatales o similares (por ejemplo, el art. 1.1. de la Convención contra la tortura), en ocasiones no (por ejemplo, el art. 7.2 del Estatuto de la Corte penal internacional); la jurisprudencia internacional es aun más vacilante. Véase SANTALLA, E., "La múltiple faceta de la tortura y los otros tratos en la jurisprudencia de la Corte Interamericana de Derechos Humanos y de los Tribunales penales internacionales", en Sistema interamericano de protección a los derechos humanos y Derecho penal internacional, vol. I, Konrad Adenauer Stiftung, Montevideo, 2010, pp. $229-262$. Para el sistema interamericano es relevante hacer notar los requisitos que la Corte ha exigido para tener por configurada la tortura: que se trate de una acción deliberada o acto intencional; que la víctima sufra dolor o angustia físicos o psicológicos severos; que exista una finalidad para infringir tortura (p. 242). 
3.3. La imprescriptiblidad de los delitos de violencia sexual contra menores es exigible pues nuestro ordenamiento jurídico está mal preparado para escuchar a las víctimas

Respecto del tercero, vale decir, la comprobación empírica que un régimen de este tipo tampoco solucionará la delicada situación de la infancia vulnerable en Chile, no parece ser un argumento decisivo para justificar esta medida. Que nuestro ordenamiento jurídico esté mal preparado para afrontar estos problemas - desde la conducta de autoridades y policías al recibir las eventuales revelaciones de menores de edad hasta como son tratados los menores en un aula de tribunales- pueden parecer atendibles como demostración y prueba del problema mayor que enfrenta nuestro país, pero no necesariamente como fundamento de la imprescriptibilidad. Si incluso en un régimen donde el paso del tiempo no tenga relevancia para su persecución los denunciantes se encontrarán, probablemente, con los mismos obstáculos que en la actualidad habla más bien a favor de introducir reformas de variada índole que incidan en ello, más que en alterar el régimen de prescripción. Reformas como la conformación de judicaturas especializadas, la capacitación de fiscales y defensores también especializados y el mejoramiento de los medios de prueba para estos delitos - tanto en cuanto a cómo se reciben los relatos de los menores vulnerados a cómo debe interpretarse de cara a la valoración del mismo- parecieran por lo demás estar más orientados a lo que la literatura especializada infantojuvenil recomienda, esto es, mejorar las posibilidades de revelación temprana. Una justicia más cercana temporalmente en el tiempo es preferible siempre a una que pueda llegar pero a una distancia temporal demasiado grande de los hechos si lo que deseamos es la tutela de los derechos de la infancia.

\section{Problemas interpretativos en CASo De AProbación} DEL PROYECTO DE LEY

Ahora, en el escenario que alguna de estas propuestas prospere, me parece relevante indicar algunas observaciones:

En primer lugar, surge la duda acerca de aquellos casos en los que se ha descubierto el delito con mucha cercanía a su comisión. ¿Se mantiene la imprescriptibilidad del mismo? Esto es importante de cara a los casos de suspensión del plazo de acuerdo con el art. 96 del Código Penal, la única manifestación de "prescriptibilidad total" de nuestro ordenamiento jurídico ${ }^{57}$. Al tratarse de un delito imprescriptible, el art. 96 no se aplicaría y, por tanto, la posibilidad de prolongar indefinidamente un proceso se vuelve muy real e innecesaria de acuerdo con los fines de la norma en caso que estas

${ }^{57}$ Se trata de un mecanismo para evitar que delitos prescriptibles se transformen en delitos virtualmente imprescriptibles solo mediante eventos interruptivos o suspensivos. Estas normas de deben probablemente al influjo de Carrara, quien veía con malos ojos cualquier mecanismo que alargase los términos prescripcionales: Carrara, F., Opuscoli di diritto criminale, vol. II, Prato, 1878, p. 102. 
modificaciones se aprueben ${ }^{58}$. Se podrá retrucar que cautela esta situación los plazos máximos de investigación del Código Procesal Penal, pero es admisible recordar que en estos casos estamos hablando siempre de investigaciones formalizadas, por lo que aquellas que se mantienen informalizadas pueden extenderse según el arbitrio del Ministerio público durante mucho tiempo.

En segundo lugar, si bien la gravedad del delito no sería aquí el argumento para declararlos imprescriptibles según lo que los propios promotores de la modificación indican, debe tomarse en consideración si se desea dar el paso a la imprescriptibilidad ${ }^{59}$. Que la violación propia e impropia y los abusos sexuales agravados sean imprescriptibles parece razonable según los argumentos de quienes defienden esta propuesta; que un abuso sexual simple o una corrupción de menores también se beneficie de esta declaración de imprescriptibilidad me parece discutible, especialmente cuando estas conductas no son reiteradas ${ }^{60}$. Una alternativa sería aquella que propone uno de los proyectos de ley actualmente en discusión en el Congreso, esto es, restringir la declaración de imprescriptibilidad para delitos de violencia sexual contra menores de 14 años, conservando la regla de suspensión para aquellos ilícitos que tengan como víctima a un menor de 18 pero mayor de 14 .

\section{Conclusiones}

Los sucesivos proyectos de ley que postulan la imprescriptibilidad de estos delitos han sido elaborados de buena fe y con un objetivo loable, cual es la protección de la infancia que sufre de delitos tan horrendos y traumáticos como los son aquellos que inciden en la libertad y la sexualidad humanas Sin embargo, la aceptación de una modificación de esta clase no solo depende de sus buenas intenciones, sino también de su ponderación con el instituto al que pretenden modificar y, por otro lado, del peso de los argumentos planteados de cara a los resultados y principios a los que aspiran. Respecto de lo primero, como hemos revisado, buena parte de la respuesta depende de la postura que se sostenga acerca del fundamento y fines de la prescripción en materia penal. Para

${ }^{58}$ Es algo que parte de la doctrina exige tratándose de normas como nuestro art. 369 quater. Véase para el caso alemán Stenberg-Lieben, D.; Bosch, N., “\$§78ff.” en: Schönke, A. y Schröder, H., StGB Kommentar, $23^{\circ}$ edición, Munich, Beck, 2010, p. 3; en España, RaGues, ob. cit., p. 153; en Chile, CaBezas, p. 395 y ss. En este caso, dicha solución no parece factible, toda vez que se declaran imprescriptibles estos plazos, lo que haría imposible revivir el plazo común de los delitos como la solución adelantada propone.

59 Pedreida, ob. cit., p. 157 y ss., considera la existencia de tres principios informadores de la prescripción: legalidad e irretroactividad, proporcionalidad de los plazos y apreciación de oficio y posibilidad de alegarla en cualquier momento. Respecto del segundo indica: "No serviría de mucho, desde el punto de vista de los derechos y garantías de los ciudadanos, que la pena y las restantes medidas restrictivas deban ser proporcionadas al hecho cometido, si posteriormente la posibilidad de imponerlas y la consiguiente situación jurídica expectante pudiera prologarse en el tiempo en forma indefinida o desproporcionada” (p. 165).

${ }^{60}$ Algo predicable también del vigente art. 369 quater. Cfr. CABEZAs, ob. cit., p. 403. 
quienes sostenemos que ella se cimienta en consideraciones a la humanidad del reo, la imprescriptibilidad solo se justifica cuando las acciones cometidas son objetivamente de un nivel de injusto sumamente grave, como en el caso de las graves violaciones a derechos humanos cometidas de preferencia por aparatos estatales o de características similares. Además, y respecto de lo segundo, si bien es atendible que la justicia brinde protección a quien después de una dolorosa reconstrucción de hechos sufridos en la infancia se atreve a denunciarlos, primero habría que comprobar que una reforma de esta naturaleza mejora la situación de las víctimas y ello es muy dudoso, como espero haber demostrado. Finalmente, esa tutela no puede desatenderse de los fines de un derecho penal racional, y que por tanto debe retirarse ahí donde el paso del tiempo ha sido excesivo. Un magisterio punitivo que se restringe temporalmente responde mejor a la idea de justicia humana, esto es, una intrínsecamente defectuosa; y porque se sabe tal, no arrastra sus consecuencias sino hasta allí donde razonablemente puede actuar.

\section{BIBLIOGRAFÍA}

1. Balmaceda, G., "La prescripción en el Derecho penal chileno", en Corral, H. (coord.), La prescripción extintiva, Cuadernos de extensión jurídica de la Universidad de los Andes, Santiago, 2011, pp. 175-194.

2. Binding, K., Handbuch des Strafrechts, Leipzig, 1885.

3. Bonet, M., La víctima del delito, McGraw-Hill, Madrid, 1999.

4. Carnevali, R., "Las políticas de orientación a la víctima examinadas a la luz del derecho penal", en Revista de Derecho de la Pontificia Universidad Católica de Valparaíso, XXVI, 2005, Semestre I), pp. 27-39.

5. Carrara, F., Opuscoli di diritto criminale, vol. II, Prato, 1878.

6. Carreón Perea, M., “Apuntes sobre la empatía y los derechos humanos”, en Iter criminis, $\mathrm{N}^{\circ} 10$, VI época, julio-septiembre 2015, pp. 79-90.

7. Cerrada Moreno, M., "La imprescriptibilidad de los delitos. Orígenes, fundamentos y regulación en el Derecho comparado y en el Derecho español”, en Cuadernos de política criminal, No 120, III, Época II, diciembre 2016, pp. 309-345.

8. Dannecker G., Das intertemporale Strafrecht, Tubingen, Mohr, 1993.

9. DíAz, A., "La experiencia de la mediación en Chile", en Polít. crim. Vol. 5, Nº 9 (Julio 2010), Art. 1, pp. 1-67.

10. Duce, M., "Algunas Reflexiones sobre los Derechos de las Víctimas en el Proceso Penal Chileno", en VV.AA., "La víctima en el sistema de justicia penal. Una perspectiva Jurídica y criminológica”, Polít. crim. Vol. 9, No 18 (Diciembre 2014), Doc. 1, pp. 739-815, p. 741.

11. Eser, A., Acerca del renacimiento de la víctima en el procedimiento penal, Ad-Hoc, Buenos Aires, 1992.

12. Fiandaca, G., y Musco, E., Diritto penale. Parte Generale, Quinta edición, Zanichelli, Bologna, 2007.

13. Fornasari, G., "Dittatori alla sbarra: il caso Bordaberry come pietra miliare della giustizia di transizione in Uruguay", en Studi in onore di Mario Romano, vol. IV, Jovene, Nápoles, 2011, p. 2295 y ss.

14. Fornasari, G., Giustizia di transizione e diritto penale, Giappichelli, Turín, 2013. 
15. Galain, P., "Reflexiones sobre alternativas a la pena y una aproximación a la alternatividad penal", en Doctrina y jurisprudencia penal. Términos anticipados, $\mathrm{N}^{\circ} 24$, Thompson Reuters, Santiago, 2015, pp. 3-36.

16. Galain, P., "Relaciones entre el derecho a la verdad y el proceso penal. Análisis de la Jurisprudencia de la Corte interamericana de Derechos humanos", en Sistema interamericano de protección de los derechos humanos y derecho penal internacional, vol. II, Montevideo, Konrad Adenauer Stiftung, 2011, pp. 249-282.

17. García Amado, J.A., “'Tienen sexo las normas? Temas y problemas de la teoría feminista del derecho", en Anuario de Filosofía del Derecho, IX, 1992, pp. 13-42.

18. García Pablos, A., Criminología, LexisNexis, Santiago, 2008.

19. Giunta, F. y Micheletti, D., Tempori cedere. Prescrizione del reato e funzioni della pena nello scenario della ragionevole durata del proceso, Turín, Giappichelli, 2003

20. Guzmán Dalbora, J.L., "Aprobación y reprobación de la reforma de los delitos contra la honestidad en Chile”, en Anuario de Derecho Penal, N 1999-2002, pp. 201-244.

21. Guzmán Dalbora, J.L., "Crímenes internacionales y prescripción”, en Temas actuales del Derecho penal internacional, Montevideo, Konrad Adenauer Stiftung, 2005, pp. 103-115.

22. Henkel, H., Introducción a la teoría del Derecho, Gimbernat, E. (trad.), Taurus, Madrid, 1968.

23. Hong, Y., Zeitablauf als Grenze des staatlichen Strafanspruchs, Peter Lang, Frankfurt, 2005.

24. Jescheck, H-H., Tratado de Derecho penal. Parte general, Mir Puig, S., y Muñoz Conde, F. (trad.), tomo II, Barcelona, Bosch, 1978.

25. López de OÑate, F., La certezza del diritto, Giuffrè, Milán, 1968.

26. Mainofer, W., Estado de Derecho y dignidad bumana, trad. Guzmán Dalbora, J.L., BdF, Montevideo, 2008.

27. Malarino, E., "Activismo judicial, punitivización y nacionalización. Tendencias antidemocráticas y antiliberales de la Corte Interamericana de Derechos Humanos”, en Sistema interamericano de protección de los derechos humanos y Derecho penal internacional, Montevideo, Konrad Adenauer Stiftung, 2010, pp. 25-64.

28. MaÑalich, JP., Terror, pena y amnistía, Flandes Indiano, Santiago, 2010.

29. Matus, J.P., "Víctima, idealismo y neopunitivismo en el Derecho penal internacional", en Revista Nuevo Foro Penal, Vol. 9, No 81, julio-diciembre 2013, pp. 139-145.

30. Matus, J.P., y Ramírez, M., Manual de Derecho penal chileno. Parte especial, Tirant lo Blanch, Valencia, 2017.

31. Medina, G., "Observaciones a proyecto de ley relativo a imprescriptibilidad de los delitos sexuales cometidos contra menores de edad”, Santiago, 16 de noviembre de 2016.

32. ORTIZ DE URbinA, I., "El renacimiento político-criminal de la víctima: una buena idea con desarrollos Problemáticos", en VV.AA., "La víctima en el sistema de justicia penal. Una perspectiva Jurídica y criminológica”, Polít. crim. Vol. 9, Nº 18 (Diciembre 2014), Doc. 1, pp. 739-815.

33. Pedreida González, F., La prescripción de los delitos y de las faltas, Centro de Estudios Ramón Areces, Madrid, 2004.

34. PeÑa, S., y Santibáñez, M., "La prescripción de delitos sexuales contra menores de edad. Modificaciones introducidas por la Ley N 20.207", Microjuris 2, enero 2008.

35. Pérez Luño, A. "La Seguridad jurídica: una garantía del derecho y la justicia", en Boletín de la Facultad de Derecho, $\mathrm{N}^{\circ}$ 15, 2000, pp. 25-38.

36. RAGUÉs, R., La prescripción penal: fundamento y aplicación, Atelier, Barcelona, 2004.

37. Recasens Siches, L., Filosofía del Derecho, Porrúa, México, 1961.

38. Rodríguez, L., Delitos sexuales, Editorial Jurídica de Chile, Santiago, 2014. 
39. Roxin, C., "La reparación en el sistema de los fines de la pena", en De los delitos y las víctimas, Ad-Hoc. Buenos Aires, 1992, pp. 129-156.

40. Saliger, F., “\$78 ff.”, en: KindhäUser, U., Neumann, U., y Paeffgen, H-U-. (Coords.) NomosKommentar StGB, $3^{\circ}$ edición, Nomos, Baden-Baden, 2010.

41. Sambale, A., Die Verjährungsdiskussion im Deutschen Bundestag, Kovac, Hamburgo:, 2002

42. SÁnchez Ostiz, P., Fundamentos de política criminal. Un retorno a los principios, Marcial Pons, Madrid, 2012.

43. Santalla, E., "La múltiple faceta de la tortura y los otros tratos en la jurisprudencia de la Corte Interamericana de Derechos Humanos y de los Tribunales penales internacionales", en Sistema interamericano de protección a los derechos bumanos y Derecho penal internacional, vol. I, Konrad Adenauer Stiftung, Montevideo, 2010, pp. 229-262.

44. Silva SÁnchez, J.M., “ ¿Nullum Crimen sine Poena? Sobre las doctrinas penales de la "lucha contra la impunidad" y del "derecho a la víctima al castigo del autor", en Derecho Penal y Criminología, vol. 29, número 86-87, 2008, pp. 149-171.

45. Silvani, S., Il giudizio del tempo. Uno studio sulla prescrizione del reato, Bolonia, Il Mulino, 2009.

46. Stenberg-Lieben, D.; Bosch, N., “\$§78ff.”, en: Schönke, A. y Schröder, H., StGB Kommentar, $23^{\circ}$ edición, Munich, Beck, 2010.

47. Vassalli, G., Formula di Radbruch e diritto penale, Giuffrè, Milán, 2001.

48. Viganó, F., "Nuove prospettive per il controllo di costituzionalità in materia penale?". Giur. cost. 2010, pp. 3017-3030.

49. Yuseff, G., La prescripción penal, Jurídica de Chile, Santiago, 2009.

50. Zaffaroni, E., En torno a la cuestión penal, Montevideo, BdF, 2005. 